
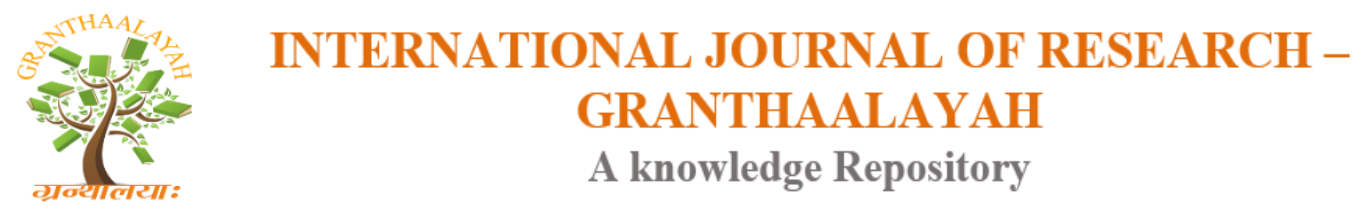

Science

\title{
AIRFOIL CONSIDERATIONS IN THE DESIGN OF HIGH PERFORMANCE, LOW REYNOLDS NUMBER PROPELLERS
}

\author{
Umunna J Reuben ${ }^{1}$, Koju Hiraki ${ }^{2}$, Miyamoto Shohei ${ }^{3}$ \\ 1,2,3 Space Dynamic Laboratory, Kyushu Institute of Technology, Japan
}

\begin{abstract}
A propeller was designed using 2D airfoil data obtained from a panel method numeric code. The propeller was designed to operate at $75 \%$ chord based Reynolds number of $20 \mathrm{k}$. At low Reynolds numbers $<40 \mathrm{k}$, there are no publicly available $2 \mathrm{D}$ airfoil force data largely because of inherent difficulty in their measurement. Theoretical prediction of the propeller's peak efficiency was 0.67 while experiment results was 0.58 . To improve the propeller efficiency by using better performing airfoils, six (6) airfoils of varying thickness and camber were studied. Three of the six airfoils were chosen and used in the design of three propellers - a single airfoil for each propeller design. The propellers were designed to operate at Reynolds number of 30k at 0.75 radius and the $2 \mathrm{D}$ airfoil force data used for the designs were obtained from a numeric code. Theoretical predictions of efficiency were all $>81 \%$ in each of the designed propellers.
\end{abstract}

\section{Nomenclature}

$\begin{array}{ll}\mathrm{T} & =\text { Thrust } \\ \mathrm{B} & =\text { Number of blades } \\ \mathrm{D} & =\text { Blade diameter } \\ \mathrm{r} & =\text { Station radius } \\ \mathrm{CD} & =\text { Drag coefficient } \\ \mathrm{CL} & =\text { Lift coefficient } \\ \mathrm{Re} & =\text { Reynolds number } \\ \mathrm{C} & =\text { Blade chord } \\ \mathrm{V} & =\text { Free airstream velocity } \\ \mathrm{J} & =\text { Advance ratio } \\ \mathrm{CT} & =\text { Thrust coefficient } \\ \mathrm{CP} & =\text { Power coefficient } \\ \eta & =\text { Efficiency }\end{array}$

Keywords: Propeller Design; Low-Reynolds Number; Airfoil Data; Xrotor.

Cite This Article: Umunna J Reuben, Koju Hiraki, and Miyamoto Shohei. (2018). "AIRFOIL CONSIDERATIONS IN THE DESIGN OF HIGH PERFORMANCE, LOW REYNOLDS 
NUMBER PROPELLERS.” International Journal of Research - Granthaalayah, 6(9), 373-384. https://doi.org/10.5281/zenodo.1451872.

\section{Introduction}

With decreasing Reynolds number $(<40)$ it becomes increasingly challenging to obtain reliable 2D airfoil force data. At these Low Reynolds number, Aerodynamic force data from experiment or numeric sources cannot be absolutely depended upon. (Selig, Guglielmo, Broeren, \& Philippe, 1995) presented experiment data of A18, BE50, and SD8030 at Reynolds number of 40k. However, while it was possible to measure lift coefficients for these airfoils, reliable measurement of drag coefficient proved difficult to obtain and are hence unavailable.

For most low inertia flows over an airfoil, that result in Reynolds number $<100 \mathrm{k}$, the presence of laminar separation degrades the performance of such airfoils. Describing the mechanism by which LSB degrades airfoil performance, (Michael, The Design of Airfoils at Low Reynolds Numbers, 1985) posits that LSB progresses forward towards the leading edge with increasing angle of attack until flow separates from the trailing edge of the airfoil leading to airfoil stall. However, airfoils can also be designed so that the LSB modifies the airfoil shape and consequently improves aerodynamic force coefficients of airfoils. (Muller, 1985) suggest that short LSB can act as a turbulator thereby improving 2D airfoil performance. (Grundy T.M, Keefe G.P, \& Lowson M.V, 2000) measured lift and drag forces acting on E61 airfoil between Reynolds number range of 25k and 60k and concluded that at high angle of attack long LSB break down into short bubbles resulting in an increase in lift and decrease in drag. Grundy further added that high acoustic activity in the vicinity of the measurement promoted a quick transitioning of flow states.

High frictional forces and low inertia associated with Low Reynolds number flows often results in adverse pressure during flow transition at the upper surface of the airfoil. The sensitivity of lowReynolds number flows makes it onerous to acquire the aerodynamic forces that govern the flow thus, reducing the quality of 2D airfoil data collected from experiments. On the other hand, 2D airfoil characteristics obtained from numeric codes are also not reliable. The limited understanding of the actual physics of low Reynolds number flows further extends to lower the accuracy of force coefficient predictions by numerical codes. (Smedresman, Yeo, \& Shyy, 2011) used Xfoil to predict the aerodynamic characteristics of MA409 at Reynolds number between 10k and 22k and used the data in the design of a propeller. In their work, uncertainties associated with 2D airfoil force data was partly blamed for observed discrepancy in the propeller performance between theory and experiment. Ultimately, inherent uncertainties from 2-D airfoil aerodynamic force data prevent accurate propeller performance prediction.

\section{Methodology}

\subsection{XFLR-5}

Xflr-5 (Drela, XFOIL: An Analysis and Design System for Low Reynolds Number Airfoils, 1989) is a numeric code that uses vortices panel method for the analysis of airfoils at low Reynolds numbers. It combines high-order panel methods with coupled interaction between viscous and inviscid layer flows to predict airfoil characteristics. An eN envelope method allows the inclusion 
of a representative boundary layer transition effects in solutions within the subsonic flow regime. Airfoils can be directly modified in Xflr-5 by direct specifying new geometric parameters such as maximum thickness and camber, trailing thickness and leading edge radius.

\subsection{XROTOR}

Xrotor is an open source propeller design tool developed at MIT. It was used throughout this work for the design of the propellers. Xrotor implements graded blade element momentum theory (Larrabee \& French, 1983), which uses Betz-Prandtl correction factor for the calculation of induced velocities and losses and Goldstein's method in which a helicoidal wake is prescribed and solved to obtained near optimum propeller twist and chord for given propeller operating conditions.

$C_{P}=\frac{P}{\rho n^{3} D^{5}}$

$C_{T}=\frac{T}{\rho n^{2} D^{4}}$

$J=\frac{V}{n D}$

$\eta=\frac{C_{T}}{C_{p}} * J$

\subsection{Propeller Design}

SD7037 was selected for the design of the propeller and its detailed geometric parameters are found in Table 1 while its 2D shape is seen in Figure 1. The lift slope and CL-CD predictions for SD7037 at Reynolds number of 20k was obtained using Xflr-5 and is shown in Figure 2.

Table 1: Geometric details of SD7037

\begin{tabular}{|l|c|c|c|c|}
\hline Airfoil & $\begin{array}{c}\text { Thickness } \\
{[\%]}\end{array}$ & $\begin{array}{c}\text { Max. Thickness Pos. } \\
{[\%]}\end{array}$ & $\begin{array}{c}\text { Max. Camber } \\
{[\%]}\end{array}$ & $\begin{array}{c}\text { Max. Camber Pos. } \\
{[\%]}\end{array}$ \\
\hline SD7037 & 9.20 & 28.30 & 3.02 & 40.42 \\
\hline
\end{tabular}
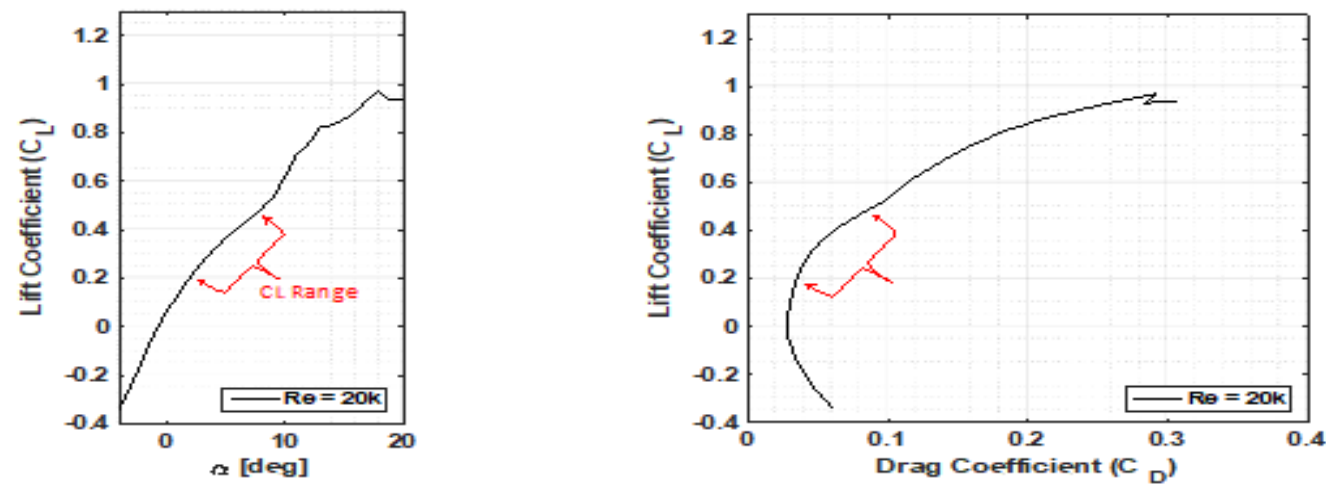

Figure 1: SD7037 2D airfoil characteristics data (Mach No=1, Ncrit $=9$ and re $=20 \mathrm{k})$ 


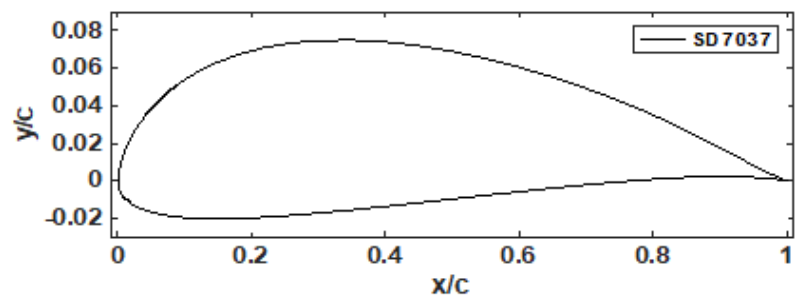

Figure 2: SD7037 profile shape

The unavailability of 2D force data at these low Reynolds number led to the absolute reliance on predictions from Xflr-5. To ensure that the blade operated within the laminar regime around design point, the choice of design lift coefficient was constrained between 0.2 and 0.5 as shown in Figure 2.

Table 2: Prepller design atmospheric condition

\begin{tabular}{|l|l|}
\hline Atmospheric Parameter & Value \\
\hline Density $\left[\mathrm{kg} / \mathrm{m}^{3}\right]$ & 1.21 \\
\hline Speed of Sound $[\mathrm{m} / \mathrm{s}]$ & 339 \\
\hline Dynamic Viscosity $[\mathrm{Kg} / \mathrm{m}-\mathrm{s}]$ & $1.78 * 10^{-05}$ \\
\hline
\end{tabular}

Table 3: Propeller design parameters

\begin{tabular}{|l|l|}
\hline Blade parameters & Value \\
\hline Number of blades & 2 \\
\hline Tip radius [m] & 0.1 \\
\hline Airspeed [m/s] & 8.0 \\
\hline Motor speed [RPM] & 3000 \\
\hline Solidity & 0.078 \\
\hline
\end{tabular}

Table 2 captures the atmospheric condition the blade was design to operate, while Table 3 outlines the blade design parameters.

An unmodified 2D profile of SD7037 was used in the design of the entire propeller. Figure 3 shows the iterated blade shape - twist and chord along the blade radius from root to hub.

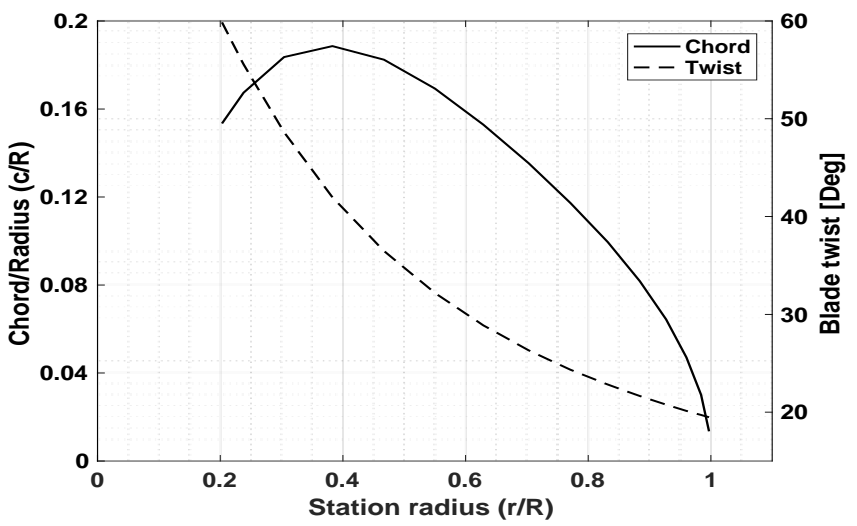

Figure 3: c/R, Twist Vs. station radius r/R 


\section{Fabrication and Experiment Test Set-Up}

The propeller was fabricated using acrylonitrile butadiene styrene material in a Mutoh 2000 3D printer. The printed propeller was hand finished to improve surface smoothness. The post-finished propeller weighed $22 \mathrm{~g}$. Figure 4(a) and (b) shows the finished propeller while Figure 4(c) shows the propeller in wind tunnel test set-up configuration.

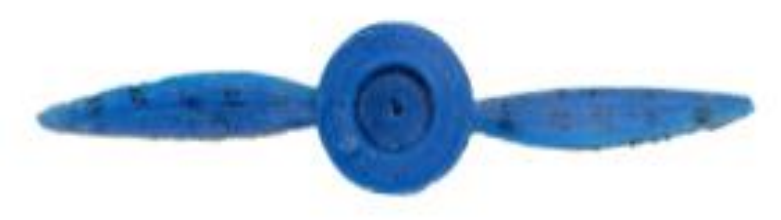

(a)

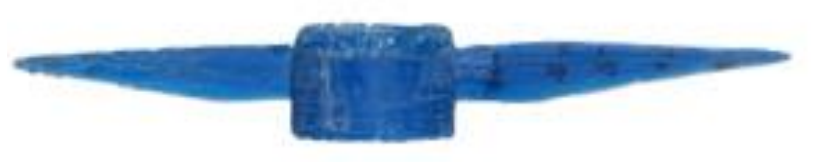

(b)

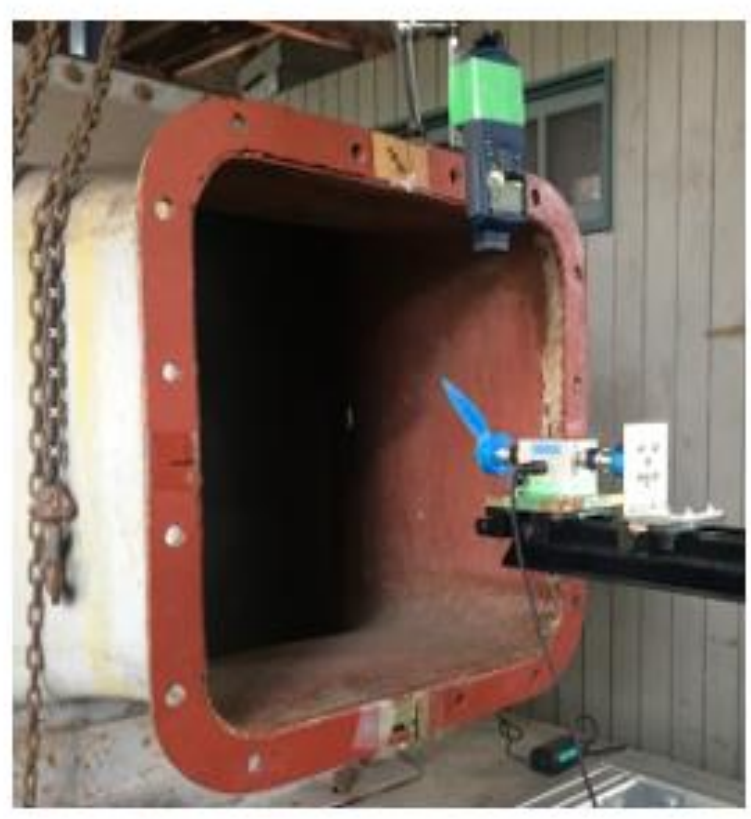

(c)

Figure 4: (a) front view of propeller, (b) Side view of propeller and (c) Propeller in test set-up

Two different test set-ups were for torque and thrust measurements. In both cases, the HT-5500 contactless tachometer was mounted about $23 \mathrm{~cm}$ above the ZS2213-22 electric motor. Power and PWM is supplied from a DC power source and an ATLAS 21A ESC respectively. The experiment setup is described in details in (Umunna, Koju, \& Shohei, 2018).

\section{Result and Discussion}

The propeller test was carried out at Kyushu Institute of Technology wind tunnel facility. The propeller was spun at a constant 2000, 3000 and 4000 RPM and at each angular velocity, the wind velocity was adjusted so that the advance ratio ranged from 0.2 and 1.3. 


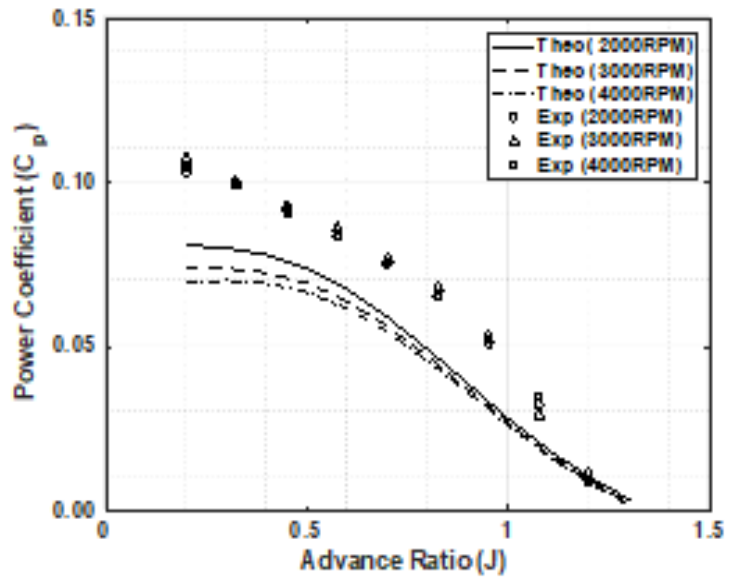

(a)

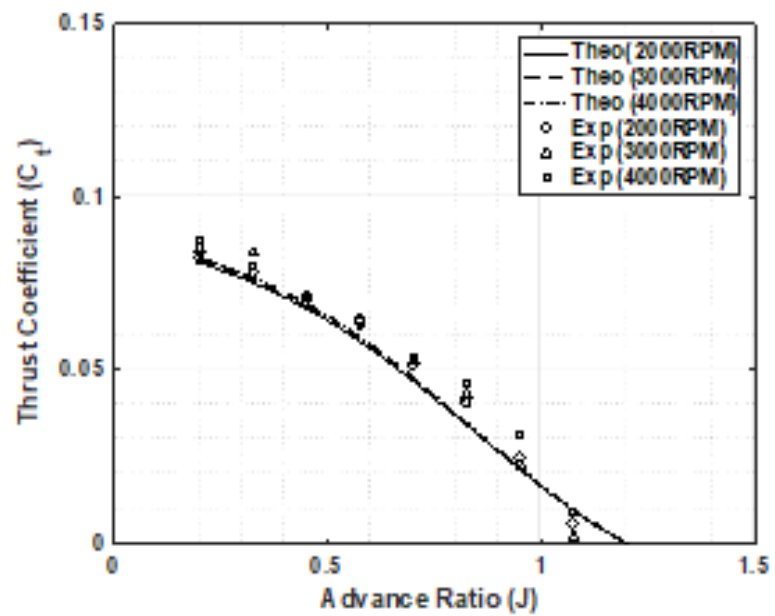

(b)

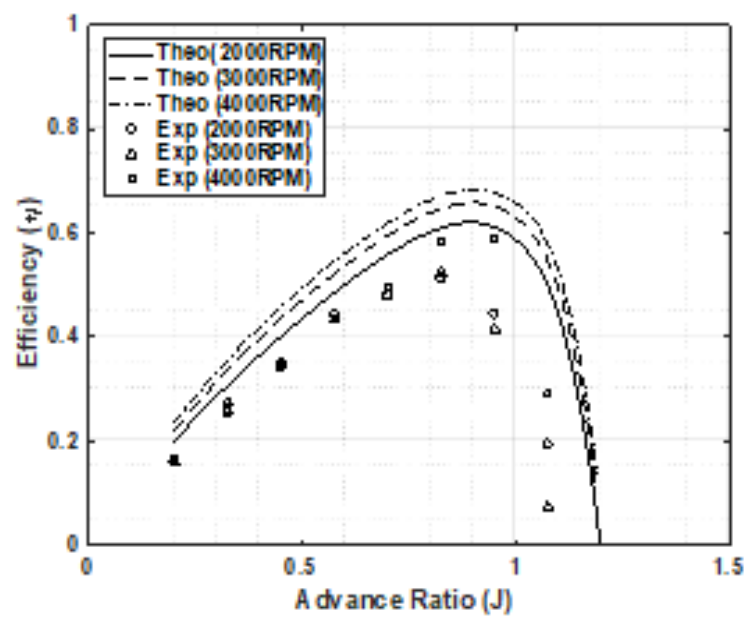

(c)

Figure 5: (a) CP Vs. J, (b) CT Vs. J and (c) Efficiency Vs. J at constant angular speeds

Figure 5(a), (b) and (c) shows theoretical and experiment power coefficient, thrust coefficient and efficiency plots respectively. Assuming $\mathrm{CP} \alpha \mathrm{Cd}$ and $\mathrm{CT} \alpha \mathrm{CL}$, it can be concluded from Figure 5(a), (b) and (c) that airfoil drag and lift coefficients were under predicted in Xflr-5 and hence, theoretical CP and CT values were correspondingly lower. However, drag coefficient was much more under estimated than was lift coefficient. The experiment peak efficiency for 4000RPM test case is 0.87 of the theoretically predicted value. Beside the observed discrepancy between theoretical performance predictions and experiment in Figure 5, the theoretical peak efficiency prediction of $67 \%$ was considered low even though the Reynolds number was 30k. A directly driven propeller design for the Black Widow (Grasmeyer \& Keennon, Development of the Black Widow Micro Air Vehicle, 2001) achieved efficiency of up to $78 \%$.

Specific airfoil parameters that improve CL/CD airfoil characteristics and thus propeller performance at low Reynolds number (<30k) were studied. Study by (Kunz J, 2003) suggested that thin airfoils perform better at low Reynolds numbers. 


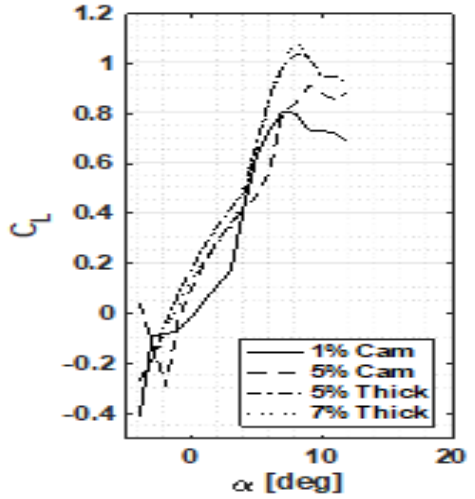

(a)

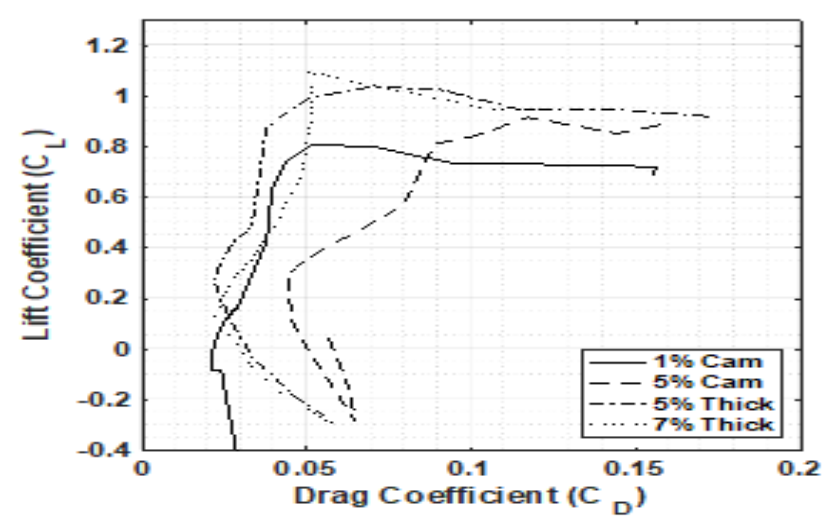

(b)

Figure 6: (a) CL Vs. Angle of attack and (b) CL Vs. CD (Mach No = 0.1, Ncrit $=9$ and $\mathrm{Re}=$ 30k)

Study was carried out using SD7037 to investigate the effects of airfoil thickness and camber at Reynolds number 30k. The maximum camber of SD7037 was changed from $3.02 \%$ to $1 \%$ and $5 \%$. Then next, the maximum thickness was decreased from $9.02 \%$ to $7 \%$ and $5 \%$. The plots of CL as a function of angle of attack and CL versus CD are shown in Figure 6(a) and (b) From the figure, it is observed that increasing camber leads to increase in the minimum drag profile of an airfoil while reducing the maximum airfoil thickness reduces the minimum drag profile. Hence, a good performing airfoil at these low Reynolds number would require certain trade off between optimum airfoil thicknesses and cambers.

Table 4: Geometric details of 6 Airfoils

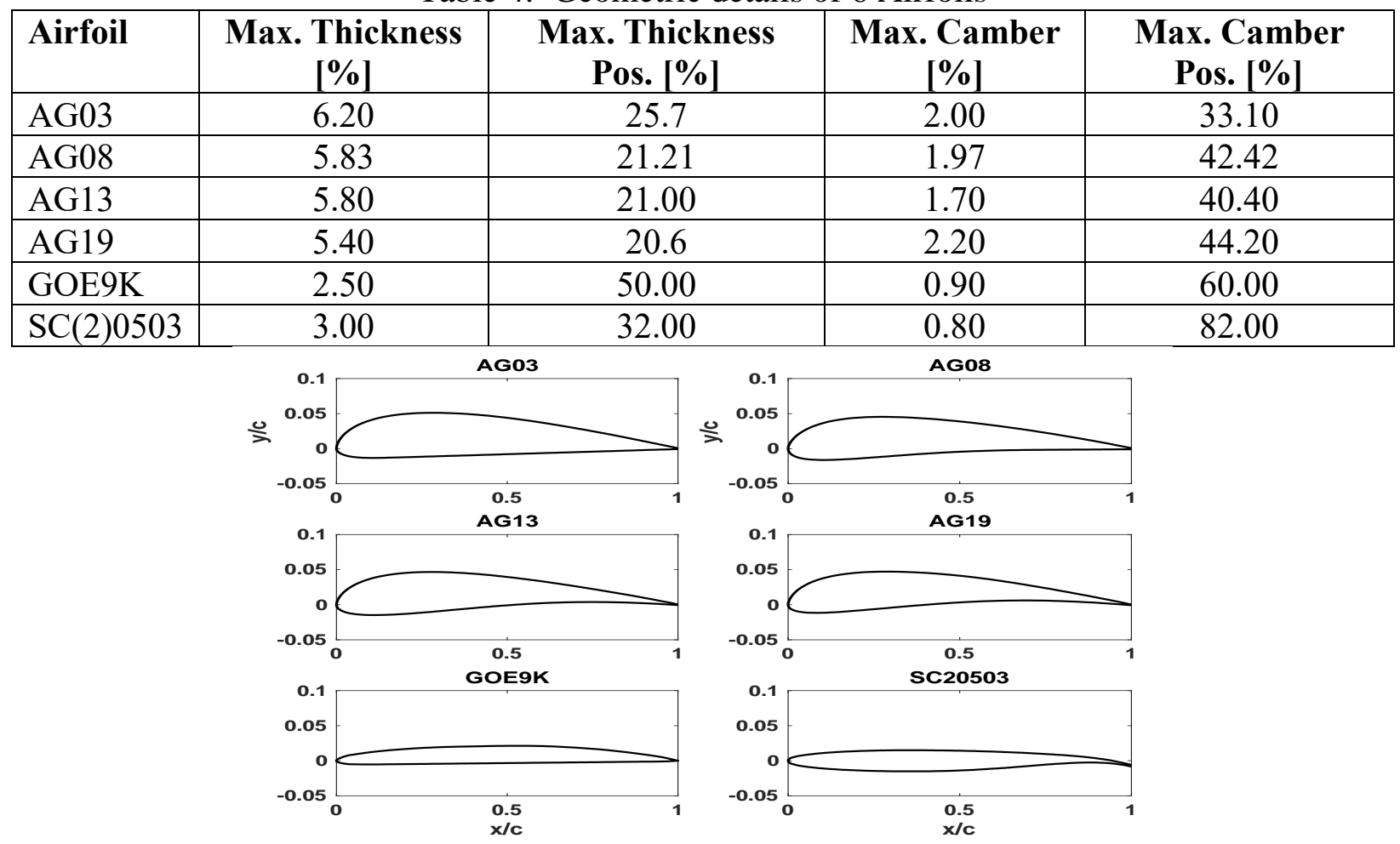

Figure 7: Profiles of 6 airfoils 
Guided by the effect of thickness and camber on airfoil performance, 6 airfoils were selected for further performance investigation. Table 4 captures the geometric parameters of the airfoils that were studied in this work. The airfoils differ in maximum thickness, maximum camber, and leading edge radius. The respective shapes of these airfoils are shown in Figure 7. Figure 8(a) and (b) shows the aerodynamic characteristics of all six (6) airfoils that were obtained using Xflr-5.

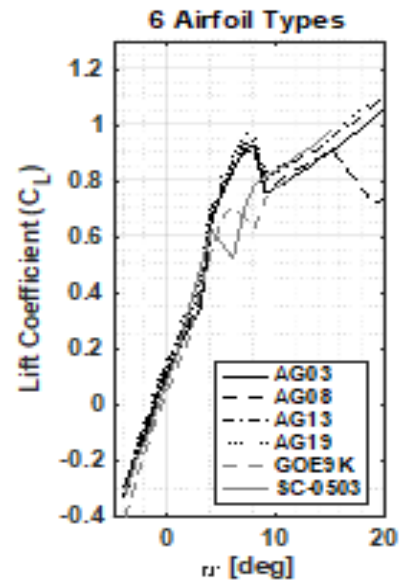

(a)

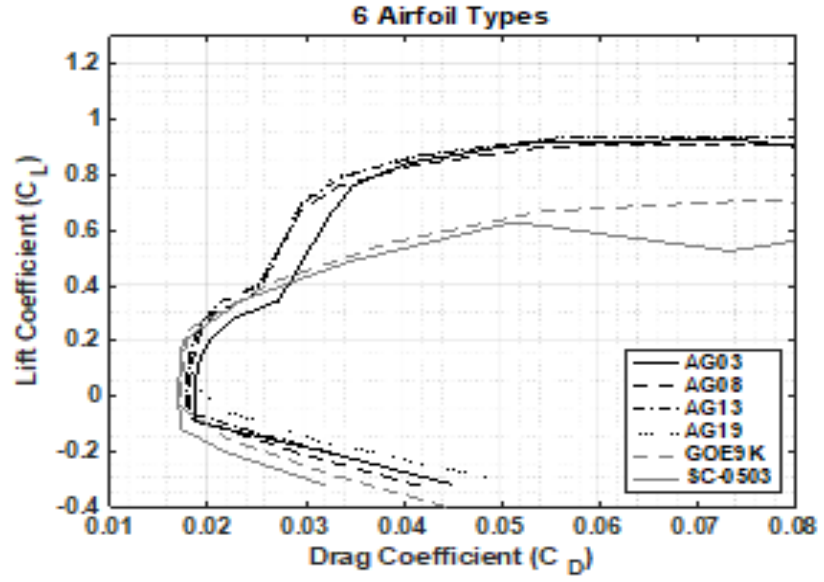

(b)

Figure 8: (a) CL Vs. Angle of attack and (b) CL Vs. CD (Mach No = 0.1, Ncrit $=9$ and $\operatorname{Re}=$ 30k)

AG19, GOE9k and SC020503 were selected for further performance evaluation in the design of blades. AG19 was chosen for its superior lift/drag and capacity to generate more lift at lower angle of attacks. GOE9k and SC020503 were both primarily chosen for their low thickness and low minimum drag profiles. The overall goal of the blade designs is to achieve over $80 \%$ efficiency at chord based Reynolds number of $30 \mathrm{k}$ calculated at $75 \%$ blade radius.

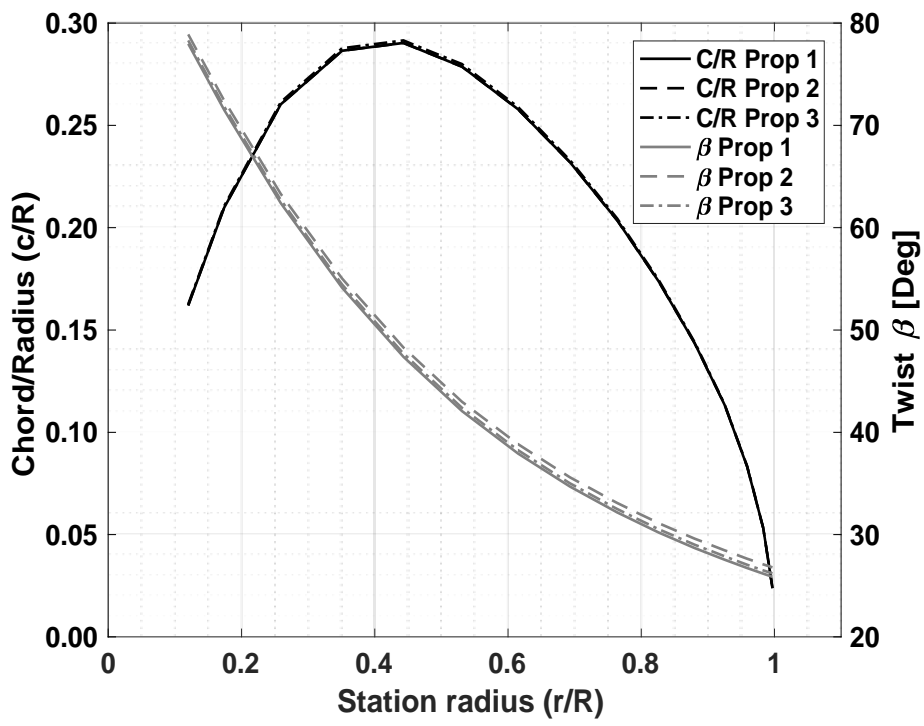

Figure 9: c/R, Twist Vs. station radius $\mathrm{r} / \mathrm{R}$ 
The design parameters found on Table 5 were used with the three selected airfoils - AG19, GOE9K and SC20503 in the iteration of three blade shapes, Prop 1, 2 and 3 respectively. Figure 9 shows the twist and chord distribution along the entire radius of each design from Xrotor. There is no observed difference in the chord distribution of the blades. However, from the mid radius to outbound region of the blades, pitch change of less than 1 degree is observed between prop 1 and 3.

Table 5: Propeller design parameters

\begin{tabular}{|l|l|}
\hline Blade parameters & Value \\
\hline Number of blades & 2 \\
\hline Tip radius [m] & 0.0875 \\
\hline Airspeed [m/s] & 12.00 \\
\hline Angular speed [RPM] & 3000 \\
\hline Solidity & 0.133 \\
\hline
\end{tabular}

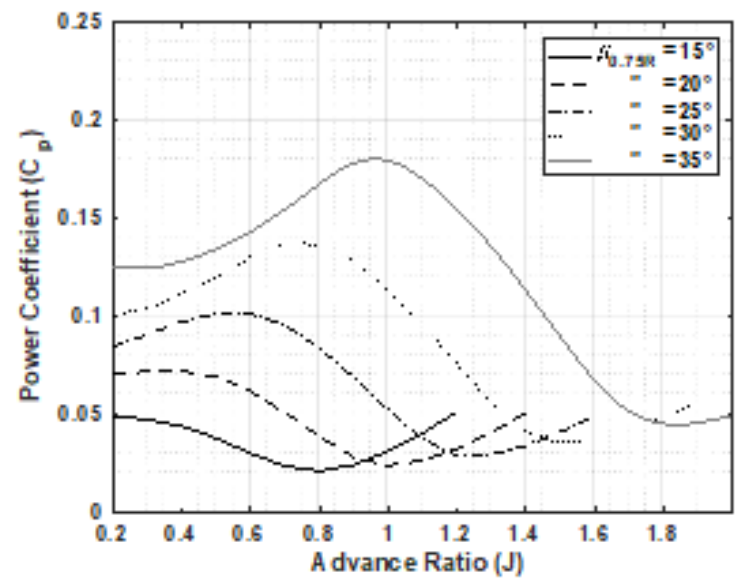

(a)

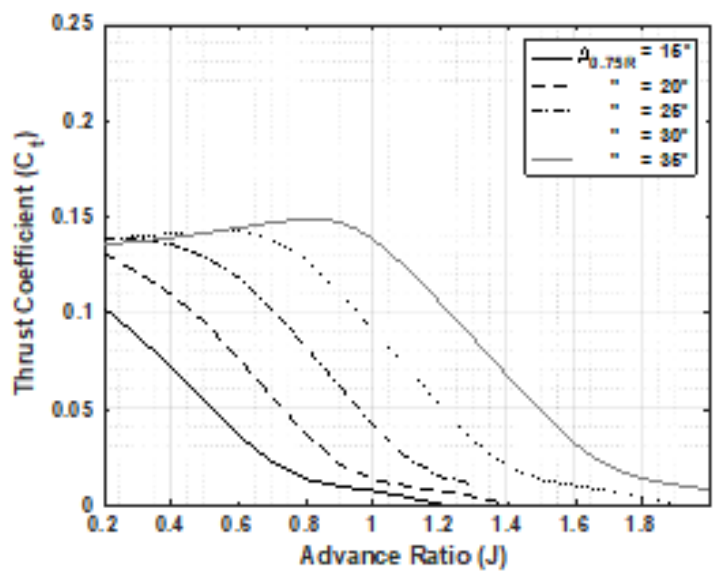

(b)

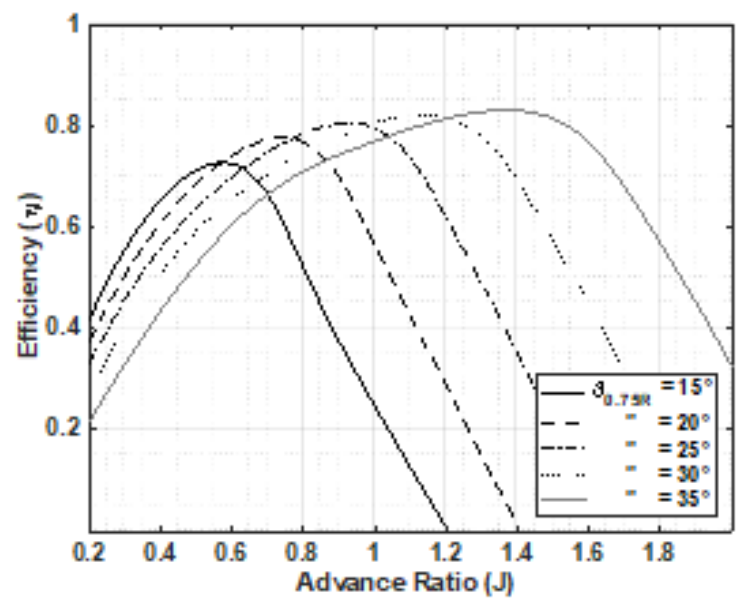

(C)

Figure 10: (a) CP Vs. J, (b) CT Vs. J and (c) Efficiency Vs. J for Propeller 1 at various pitch angles $($ motor speed $=3000$ RPM $)$ 


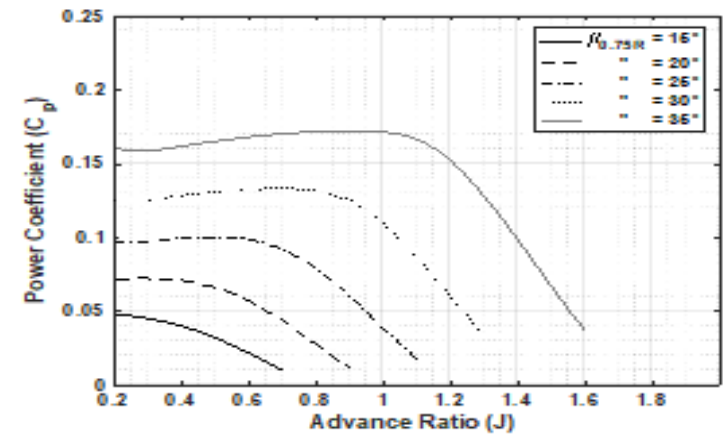

(a)

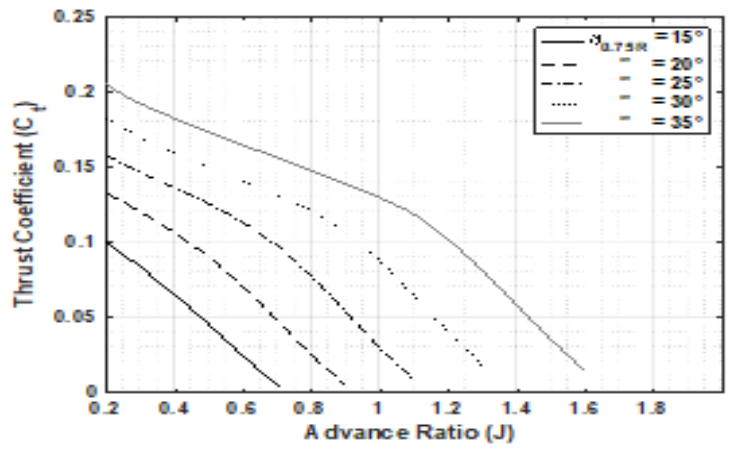

(b)

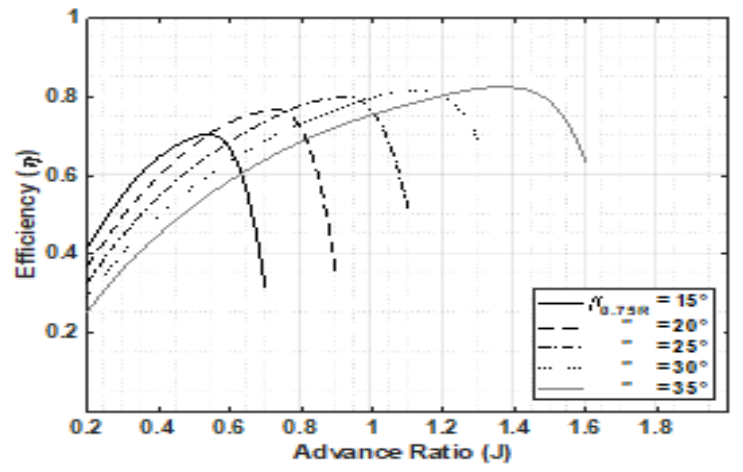

(c)

Figure 11: (a) CP Vs. J, (b) CT Vs. J and (c) Efficiency Vs. J for Propeller 2 at various pitch angles $($ motor speed $=3000 \mathrm{RPM}$ )

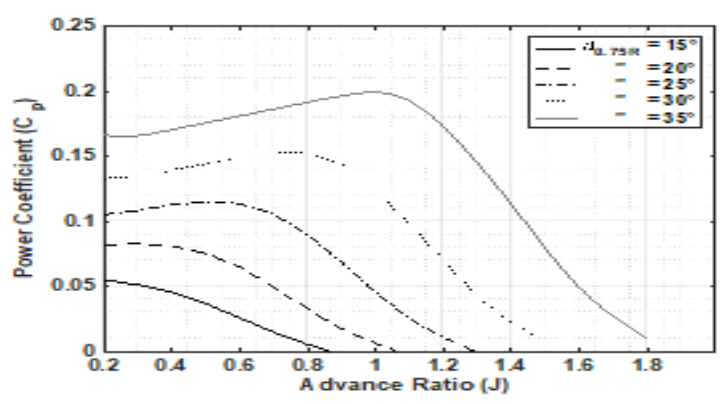

(a)

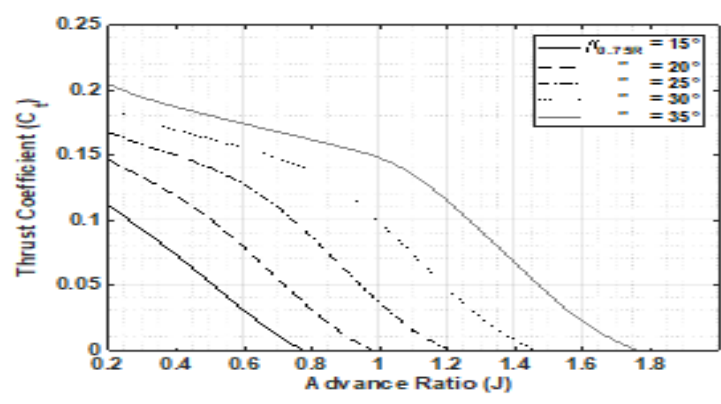

(b)

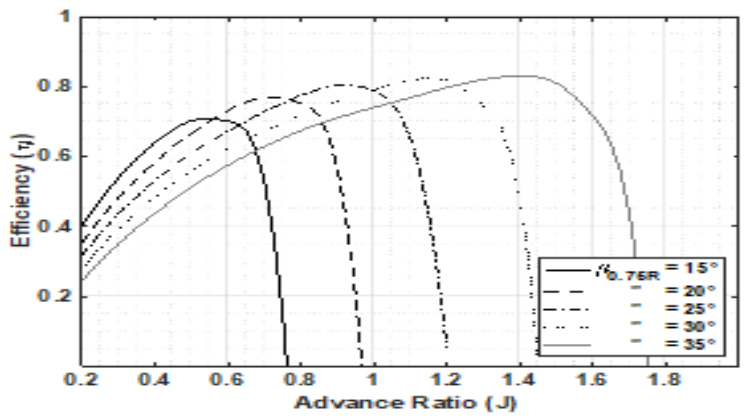

(c)

Figure 12: (a) CP Vs. J, (b) CT Vs. J and (c) Efficiency Vs. J for Propeller 3 at various pitch angles $($ motor speed $=3000$ RPM) 
The Performance of each blade design was evaluated across a range of advance ratios and blade pitch, which was calculated at $75 \%$ radius. Figure $10(a)$, (b) and (c) shows the theoretical performance prediction of propeller. The predicted propeller efficiency reached $81 \%$ at pitch angle of 35deg as seen in Figure 10(c). The lift superiority of AG19 observed in Figure 10(a) delayed stall and eventually resulted in a wider range of advance ratio coverage. Similarly, propeller 2 reached efficiency of $81 \%$ as seen in Figure 11(c), however, limited maximum lift attainable by the airfoil correspondingly restricts the advance ratio. Propeller 3, achieved efficiency of $83 \%$ as shown in Figure 12(c).

All three airfoil used in the design of three propellers have maximum thickness less than $5.5 \%$ of chords and minimum drag coefficients $<0.019$, as result, the predicted propeller efficiency increased dramatically to above $80 \%$. Thus, the performance of low Reynolds number propellers can be greatly enhanced by reduction in the airfoil profile drag by reducing thickness, camber or both while ensuring that lift generation capabilities is not compromised. For applications where a large flight envelope range is not desired, for example air vehicles that may be directly deployed into their operation environment or do not require ground takeoff's, airfoils with high stall angles may be traded for thin and low cambered airfoils.

\section{Conclusion}

A propeller was designed using 2D airfoil data obtained from a numeric code that uses vortices panel method. The propeller was designed to operate at $75 \%$ chord based Reynolds number of $20 \mathrm{k}$. Theoretical efficiency of the fabricated propeller achieved a maximum of $67 \%$, while experiment data from efficiency was up to $13 \%$ less than theoretically predicted value. Inaccurate prediction of 2D airfoil force data was the major contributor to the discrepancy between experiment and theory. However, propeller deflection and manufacturing limitations were also contributors.

To improve the overall propeller efficiency, three out of six airfoils evaluated were selected on the basis of their performance at 30k Reynolds numbers and used in the design of 3 propellers. All three propellers showed more than $81 \%$ theoretical efficiency. It was concluded that airfoils of $<3 \%$ thickness may be a preferred choice for air vehicles operating in low Reynolds environments where there is no requirement to operate in large flight envelope. For instance, if the vehicle would be deployed into its operation environment and thus, there is no need for ground takeoff.

\section{Declaration of Interests}

None

\section{Acknowledgement}

This work was done in the collaborative research 17UKSG-007330 with Japan Aerospace and Exploration Agency.

\section{References}

[1] Selig, Michael., et al. Summary of Low-Speed Airfoil Data. Virginia: SoarTech, 1995.

[2] The Design of Airfoils at Low Reynolds Numbers. Michael, Selig. Nevada: AiAA, 1985. 85-0074.

[3] Muller, Thomas J. Low Reynolds Number Vehicles. University of Notre Dame. Indiana: Advisory Group For Aerospace Research And Development, 1985. 
[4] Effects of Acoustic Disturbances on Low Re Airfoil Flows. T.M, Grundy, Keefe G.P and Lowson M.V. Notre-Dame: AIAA, 2000.

[5] Design, Fabrication, Analysis and Testing of a Micro Vehicle Propeller. Smedresman, Adam, Yeo, Derrick and Shyy, Wei. Hawaii: AIAA, 2011. AIAA 2011-3817.

[6] Drela, Mark. XFOIL: An Analysis and Design System for Low Reynolds Number Airfoils. [ed.] T.J Muller. 1989, Vol. 54.

[7] Minimum induced loss windmills and propellers. Larrabee, E.Eugene and French, Susan E. 1-3, 1983, Journal of Wind Engineering and Industrial Aerodynamics, Vol. 15, pp. 317-327.

[8] Non-Linear Effects of Airfoil Force Data on Design Performance of Low-reynolds Number Propeller. Umunna, Reuben, Koju, Hiraki and Shohei, Miyamoto. s.l.: IJRG, 2018, Vol. 6.

[9] Development of the Black Widow Micro Air Vehicle. Grasmeyer, Joel and Keennon, Matthew. Reno: AIAA, 2001.

[10] J, Kunz P. Aerodynamics and Design for Ultra-Low Reynolds Number Flight. Stanford University. 2003. Dissertation.

*Corresponding author.

E-mail address: p595109j@ mail.kyutech.jp 